\title{
Animal rights lobby cashes in
}

THERE is still no word from the British Government on the progress of its new animal experimentation legislation. More than a year has passed since the release of the White Paper - "Scientific Procedures on Living Animals"' (see Nature 303, 191; 1984) - containing draft proposals for the replacement of the Cruelty to Animals Act of 1876 with more effective and less anachronistic controls. In that year, the views and critical comments of concerned organizations have been collected and assimilated. Moderate animal rights groups are now hoping that a suitable response, in the form of a supplementary White Paper, will be published by the end of the year.

Meanwhile, the more extreme animal rights groups, including the Animal Liberation Front (ALF), have stepped up their campaign against animal experimentation with paramilitary style attacks on selected institutions. Government laboratories have been forcibly entered, equipment damaged and records essential to research stolen. Pharmaceutical companies have also suffered harassment and intimidation of their employees. And Mr David Mellor, Under-Secretary at the Home Office and the man principally responsible for preparing the new legislation, has become the object of escalating harassment which, he says, has included threats on his life. Meanwhile, a coalition of organizations including Animal Aid and the British Union for the Abolition of Vivisection, has drawn up a list of minimum requirements which, it says, must be part of the legislation to replace the archaic 1876 act. It wants to see a complete ban on tests of cosmetics, alcohol and tobacco, behavioural and psychological tests, warfare experiments and, more specifically, two routine tests it considers particularly offensive: the Draize eye test in which irritants are put in the eyes, usually of rabbits, until damage is caused, and the so-called LD50 toxicity test in which animals are given increasing doses of a test substance until half have died.

The coalition is unlikely to be satisfied with the proposed measures which, in order not to hamstring British companies by prohibiting experiments that competing foreign companies would be free to carry out, avoids a complete research ban. The proposals differ from the old act in the following ways:

- The 1876 law, which only governs experiments, will be extended in scope to address procedures such as the production of antisera and the passaging of tumours.

- A statutory Animal Procedures Committee will replace the previous nonstatutory body.

- Laboratory animals will have to be obtained from registered establishments, outlawing the use of strays.
- The 1876 law required all animals recovering from anaesthesia to be compulsorily killed but, today, some surgical procedures are relatively mild and anaesthesia is used principally to immobilize a subject. This requirement is to be waived in such circumstances.

- The conditions in which animals are maintained will be regulated.

- Home Office inspectors will need to be satisfied that a procedure is justifiable and that no satisfactory alternative to the use of animals is feasible, that the minimum number of animals is used and that the least possible suffering is caused.

The Royal Society for the Prevention of Cruelty to Animals (RSPCA) is generally critical of these proposals. The White Paper advocates the continuation of the present rule that "if an animal is found to be suffering severe pain which is likely to endure, it shall at once be killed"'. But, RSPCA points out, since the Home Office itself admits it cannot define the terms "pain", "severe" or "enduring", the inclusion of these words in such a pivotal role undermines the credibility of the proposals. Other organizations are also insistent that the pain question be dealt with. The Fund for the Replacement of Animals in Medical Experiments (FRAME) is commited to reducing animal experiments to a minimum and to finding alternatives to animals. In a study, prepared in conjunction with the British Veterinary Association (BVA) and the Committee for the Reform of Animal Experimentation (CRAE) and supplied to the Home Office, it distinguishes two types of pain: unexpected pain inflicted during an

\section{Bird books safe}

\section{Washington}

A UNIQUE collection of environmental and natural history documents, including the only known intact copy of the "elephant folio" edition of John Audubon's Birds of America, has been granted a reprieve from the auction block. The National Audubon Society had planned to close the library and sell off part of it to raise funds, but the society has now changed its mind after word of the plan leaked out and provoked a minor squall among members and the American Library Association. Many were upset that the board of directors of the society did not consult its membership before taking the decision at its May meeting, and that the society has in fact still made no official announcement on the subject.

According to the library association, the collection, which is housed in the society's New York offices, contains many works on ornithology, wildlife preservation and conservation which can be found together in

\section{Britain leads the way}

DESPITE the flak aimed at the government by animal rights organizations, Britain is ahead of most other European countries in the area of animal experimentation reform. The 21-nation Council of Europe has been trying, since 1978 , to perfect a "Convention for the protection of animals used for experimental purposes" (Nature 302,$284 ; 1983$ ) and the convention is likely to be less strict than the British law. Nevertheless, a European accord on the political horizon could go some way to allaying the fears of pharmaceutical companies that what they perceive as an over-zealous British initiative.

The ageing British act also has admirers in the United States. In a Commentary appearing in Nature later this month, an animal rights campaigner argues that the British approach to animal experimentation is much more humane than the US approach. Two bills aiming to improve matters are at present bogged down in the US Congress, with the powerful industrial lobby content to keep them there.

experiment, and pain and suffering which is the inevitable consequence of an experiment. In the former situation, FRAME says, the animal should be killed as required by the 1876 act. In the latter situation, permission should be given only in very special circumstances when the experiment is of great importance to human or animal health.

Both the RSPCA and FRAME are unwilling to be too critical of the Home Office until they see its revised proposals and can assess to what extent their advice has been heeded. The new bill could reach Parliament during next year or in 1986 .

Marcus Chown

no other library. It also includes a number of unduplicated nineteenth century works.

The library dispute appears to be part of larger tensions that have been growing between the society's membership and its staff on the one hand and its leadership on the other. Under the presidency of Russell Peterson, the society has become increasingly involved in what is known in the trade association business as "government affairs", that is, lobbying. Peterson attempted to move the entire office to Washington several years ago, but abandoned the plan. Peterson has also involved the society in such issues as global population and nuclear war. Many staff members are known to be displeased with what they see as a swelling bureaucracy including some 25 vice-presidents - which has grown at the expense of basic programmes.

Although the library will remain intact for the time being, it has been closed to the public and its full-time librarian assigned to new duties within the society.

Stephen Budiansky 